\title{
Psicanálise, Vida Loka e Rodas de Escrita com Adolescentes Privados de Liberdade
}

\author{
Simone Zanotelli Heissler ${ }^{1}$ \\ ${ }^{1}$ Universidade Federal do Rio Grande do Sul, RS, Brasil.
}

\author{
Rose Gurski ${ }^{1}$ \\ ${ }^{1}$ Universidade Federal do Rio Grande do Sul, RS, Brasil.
}

Resumo: Este artigo parte de uma experiência de pesquisa-intervenção realizada com jovens que cumpriam medida de privação de liberdade em uma instituição socioeducativa. Inicialmente, ao circular pela instituição, inquietou-nos o número expressivo de frases e escritos de autoria dos jovens internos presentes nos muros e paredes do local. Ali, os meninos contavam sobre a vida loka, expressão que, conforme relatos, traduz uma vida sem limites, perigosa e com riscos. Do encontro com os escritos da vida loka, passamos a questionar: de que modo esses jovens narram suas histórias? Quais os efeitos de sujeito que podem advir da escuta dos diferentes modos de escrita dos adolescentes? Nesse contexto, construímos as Rodas de Escrita, um dispositivo que nasce do enlace entre a escuta psicanalítica e os efeitos ético-metodológicos do tema da experiência em Walter Benjamin. Nas Rodas, os adolescentes eram convidados a escrever e falar livremente sobre questões que lhes interessavam. O pesquisador que conduziu as Rodas registrava os dados conforme o dispositivo dos diários de experiência. Para análise dos relatos dos diários de experiência, bem como dos escritos dos adolescentes, utilizamos a leituraescuta. A partir da análise do material da pesquisa, tensionamos a posição que esses jovens têm ocupado no laço social e sua aproximação com a figura do homo sacer. Também refletimos sobre a aposta na escuta e na circulação da palavra, por meio das Rodas de Escrita, como um modo de produzir efeitos de sujeito, fazendo, por exemplo, deslizar brevemente a posição de vida loka para vida loka tb ama.

Palavras-chave: Psicanálise, Rodas de Escrita, Adolescentes, Socioeducação.

\section{Psychoanalysis, Vida Loka and Writing Wheels with Adolescents Deprived of Liberty}

\begin{abstract}
This article is based on a research-intervention experience with adolescents in deprivation of liberty in a socio-educational institution. Initially, when circulating by the Institution, we were disturbed by the expressive number of writings on the walls of authorship of adolescents. There, the boys told about the vida loka, an expression that, according to reports, translates a life without limits, dangerous, with risks. From the encounter with the writings of vida loka, we come to question: how have these young people managed to narrate their stories? What are the possible effects of the subject that can come from the listening of the different ways of writing of the adolescents? In this context, we constructed the Writing Wheels, a device that emerges from the link between psychoanalytic listening and the ethical-methodological effects of the theme of the experience in Walter Benjamin. At Wheels, teens were invited to write and speak freely on issues that interested them. The researcher who conducted the Wheels recorded the data according to the device of the experience journals. For the analysis of the reports of the experience journals, as well as the writings of adolescents, we used reading-listening. From the analysis of the research material, we stress the position that these young people have occupied
\end{abstract}


in the social bond and its approximation with the figure of homo sacer. We also reflect on the bet on listening and word circulation, through the Writing Wheels, as a way of producing subject effects, making, for example, briefly slide the position of vida loka to vida loka tb ama.

Keywords: Psychoanalysis, Writing Wheels, Adolescents, Socioeducation.

\title{
Psicoanálisis, Vida Loka e Ruedas de Escritura con Adolescentes Privados de Libertad
}

\begin{abstract}
Resumen: Este artículo parte de una experiencia de investigación-intervención realizada con jóvenes que cumplían medida de privacion de libertad en una institución socioeducativa. Inicialmente, al circular por la Institución, nos inquietó el número expresivo de escritos en los muros y paredes de autoria de los adolescentes. Allí, los niños contaban sobre la vida loka, expresión que, según relatos, traduce una vida sin límites, peligrosa y con riesgos. Del encuentro con los escritos de la vida loka, pasamos a cuestionar: ¿de qué modo esos jóvenes narran sus historias? ¿Cuáles son los efectos de sujeto que pueden provenir de la escucha de los diferentes modos de escritura de los adolescentes? En ese contexto, construimos las Ruedas de Escritura, um dispositivo que nace del enlace entre la escucha psicoanalítica y los efectos ético-metodológicos del tema de la experiencia en Walter Benjamin. En las Ruedas, los adolescentes eran invitados a escribir y hablar libremente sobre cuestiones que les interesaban. El investigador que condujo las Ruedas registraba los datos según el dispositivo de los diarios de experiência. Para el análisis de los relatos de los diários de experiencia, así como de los escritos de los adolescentes, utilizamos la lectura-escucha. A partir del analisis del material de la investigación, problematizamos la posición que estos jóvenes han ocupado en el lazo social y su aproximación com la figura del homo sacer. También reflexionamos sobre la apuesta en la circulación de la palabra, a través de las Ruedas de Escritura, como um modo de produzir efectos de sujeto, haciendo, por ejemplo, deslizar, brevemente, la posición de vida loka para la vida loka tb ama.
\end{abstract}

Palabras clave: Psicoanálisis, Ruedas de Escritura, Adolescentes, Socioeducación.

\section{Introdução}

O presente artigo parte de uma experiência de pesquisa-intervenção ${ }^{1}$ realizada com jovens do sexo masculino que cumpriam medida de privação de liberdade em uma instituição socioeducativa. A pesquisa originou-se de outros estudos que enlaçam a Psicanálise e a Socioeducação a partir do a partir do eixo Psicanálise, Educação, Adolescência e Socioeducação do NUPPEC ${ }^{2}$.

No âmbito do NUPPEC, temos nos ocupado em refletir acerca dos modos de representação da adolescência contemporânea, especialmente no que se refere à violência juvenil. Nesse sentido, desde meados de 2015 temos construído uma parceria com a instituição responsável pela execução de medidas socioeducativas de privação e restrição de liberdade em nosso Estado. Inicialmente, isso se deu por meio de Rodas de R.A.P. (Gurski \& Strzykalski, 2018b, 2018c; Gurski, Strzykalski \& Rosa, no prelo), um espaço que busca oferecer condições para que a palavra dos adolescentes internos possa circular em conjugação com narrativas musicais por eles demandadas.

A partir do que escutamos nas primeiras Rodas de R.A.P., ocorreu-nos que seria interessante que alguns

\footnotetext{
${ }^{1}$ Esta pesquisa foi financiada pelo Conselho Nacional de Desenvolvimento Científico e Tecnológico (CNPq), por meio do Edital Universal CNPq 447672/2014-2, com aprovação do comitê de ética por meio do CAAE 30730014.1.0000.5334.

${ }^{2}$ O NUPPEC (Núcleo de Pesquisa em Psicanálise, Educação e Cultura) é uma ação conjunta de docentes do Programa de Pós-Graduação em Psicanálise: Clínica e Cultura e do Programa de Pós-Graduação da Faculdade de Educação da UFRGS. Para mais informações: www. ufrgs.br/nuppec e www.facebook.com/nuppec.
} 
pesquisadores de nosso grupo pudessem circular pela instituição de modo mais amplo, isto é, para além da sala em que as Rodas aconteciam. Nesse contexto, passamos um período de quatro meses circulando livremente por uma das unidades da instituição com o propósito de familiarizarmo-nos com o cotidiano institucional. Caminhando pelos corredores, fomos conhecendo um pouco mais do funcionamento da socioeducação e das relações que se estabelecem entre os agentes socioeducativos e os jovens acautelados.

Ao caminhar pelas salas, dormitórios, cozinhas, refeitórios e banheiros, fomos vivenciando diferentes cenas, cheiros, sensações e imagens. Há uma predominância da cor cinza nas paredes descascadas pela umidade. De forma geral, não nos pareceu um ambiente acolhedor. Ao mesmo tempo, paradoxalmente, notamos hortas bem cuidadas entre alguns belos quadros e desenhos pendurados nas paredes.

A unidade que conhecemos contava com um número quase sempre elevado de meninos, divididos em três alas. Os olhares curiosos estavam sempre presentes, assim como o desejo de descobrir o que estávamos fazendo ali e se tínhamos informações sobre o andamento de suas medidas, entre outros pedidos. Não raro, tivemos a oportunidade de estender o encontro com alguns desses jovens durante o circular pela instituição, momentos em que escutamos suas angústias e solicitações por espaços de fala.

Percebemos, também, que era por meio de cartas e bilhetes que muitos jovens conseguiam comunicar seus sentimentos. Às vezes, os meninos nos entregavam pedaços de papel com produções escritas, ou ainda nos paravam para que escutássemos seus escritos, como o menino que leu as rimas criadas em meio aos corredores.

Seguindo nosso percurso, tivemos um encontro bastante impactante: depois de algumas semanas, quando já estávamos mais ambientadas e conhecidas pelos agentes socioeducativos e pelos adolescentes, um novo cadeado foi aberto. Passamos a ter acesso à parte interna da ala em que se localizam os dormitórios dos adolescentes. Dentro desses espaços, encontramos a mesma crueza que compõe a instituição: colchões no chão frio, janelas quebradas, roupas amontoadas nos cantos. Paradoxalmente, nas paredes desse ambiente precário, surgia com vivacidade o colorido pintado pelas frases escritas pelos meninos. Em grafite, misturavam-se letras de rap, poemas, frases de amor e de revolta. Novamente, percebemos a escrita presentificando-se e colorindo nossa visão. Através das paredes, parecia ser contada a vida loka, expressão que, conforme relatos dos jovens, traduz uma vida sem limites, perigosa, com muitos riscos. Esses escritos da vida loka acabaram nos levando a refletir sobre o que vinha sendo expresso nos modos encontrados pelos adolescentes de contar suas histórias, bem como sobre os espaços para a escuta dessas vidas.

Percebemos, assim, que naquele lugar de tantas ambiguidades, de tanta aridez, no lugar que, conforme a fala de uma agente socioeducativa, "todos querem esquecer", a palavra insistia em se apresentar, já que ela estava por todos os lados: pela fala, pelas cartas, grifadas/grafitadas entre muros e paredes. Nos surpreendemos com tudo que parecia estar sendo dito e não escutado, eram sensações e sentimentos escritos - mas não lidos.

Nesse contexto, passamos a refletir sobre o modo como a escrita nos muros e paredes da instituição parecia evidenciar a expressão do mal-estar dos jovens. É nesse sentido que temos refletido que o desejo de analista nos leva não somente à escuta do particular do sujeito, mas, também, à relação do sujeito (do inconsciente) com o laço social no qual vive. O desamparo e a vulnerabilidade do ser humano, assim como as tensões entre as pulsões e a cultura, descritos por Freud em Mal-estar na civilização (1930), são questões constantes que sofrem variações de nuances de acordo com as contingências de cada tempo social e de cada singularidade. Escutar as produções desses sujeitos que testemunham, com suas vidas nuas, os efeitos das novas formas de barbárie, de destruição e de segregação, têm sido um modo de atualizar a psicanálise, fazendo-a dialogar com as novas formas de desamparo em nosso tempo social.

Pensamos, então, que fazer falar a palavra escrita e escutar o que os adolescentes escrevem por entre muros e paredes, a partir da ética psicanalítica, poderia ser um modo de abrir espaço para o reconhecimento de algumas nuances de suas subjetividades, das diferenças que portam e de seus modos de criar. Sendo assim, passamos a interrogar: quais efeitos poderiam advir da escuta da escrita, das palavras, a partir da constituição de um leitor (pesquisador)? Criar um espaço para a transmissão da experiência (Benjamin, 1936/2012), constituindo um modo de compartilhamento do que esses jovens vivem, seria uma forma 
de suspendê-los, ainda que brevemente, de um lugar de invisibilidade e de vida nua (Agamben, 2010)? Foi assim que começamos a esboçar o dispositivo que nomeamos como Rodas de Escrita.

\section{A vida nua como presença na instituição socioeducativa}

Algumas cenas e relatos que escutamos enquanto circulávamos pela instituição nos convocaram, novamente, a reflexões acerca da invisibilidade e da vida nua, conceitos desenvolvidos por Agamben (2010). Partimos de algumas noções desse autor que, articuladas à psicanálise e à política, nos levam a questionar a relação entre o conceito de vida nua, a figura do homo sacer e os adolescentes em conflito com a lei (Gurski, 2017).

Agamben (2010) evoca o conceito de vida nua para construir seu entendimento a respeito dos sujeitos que vivem às margens da sociedade, incluídos pela via da exclusão. Segundo Viñar (2009), a vida nua, termo que Agamben toma de Walter Benjamin, equivaleria à vida do sujeito pertencente a um mundo de pura necessidade, sem lugar para ilusão, fantasia, planos de vida e construções. Agamben (2010) enfatiza uma preponderância da vida nua e afirma que os regimes de governo contemporâneos têm exercido essa forma de poder, por vezes, travestido de defesa da vida - o que, na realidade, reduz ela à sua modalidade biológica, ou seja, à mera sobrevivência.

Em "Homo sacer: O poder soberano e a vida nual", Agamben (2010) busca no direito romano antigo a figura do homo sacer, evidenciando o ponto entre a biopolítica e o poder soberano exercido pelo campo jurídico que acaba colocando alguns indivíduos sob a perspectiva da vida nua. O homo sacer seria a representação dessa vida nua, tornando-se, desse modo, um sujeito matável por ordem do poder soberano juridicamente construído - poder esse que torna o sujeito excluído e exterminável, incluído sob essa perspectiva no laço social (Martins, 2014).

A partir desses pressupostos, Agamben (2010) aponta que cada sociedade define quais vidas são ou não dignas de serem vividas, quais serão os seres que ocuparão o lugar de exclusão, de homo sacer. Dito de outro modo, cada sociedade define quem serão aqueles que serão abandonados à própria sorte, que podem ser apagados aos olhos os outros, incluídos então pela via da exclusão, da exceção, e, portanto, invisibilizados.
Os laços entre a psicanálise e as interpretações de Agamben (2010) sobre a sociedade contemporânea levam-nos a considerar os jovens autores de atos infracionais como expressões da figura do homo sacer, pois esses, conforme nos diz Gurski (2017), parecem-nos sujeitos que habitam uma zona de indistinção entre a vida e a morte em seu dia a dia, como se tivessem a dimensão da descartabilidade de suas existências.

Para Rosa (2016), ao se encontrarem com a impotência perante o laço social que insiste em barrar e impedir o acesso à lógica fálica e ao desejo, os sujeitos emudecem, construindo, assim, uma espécie de apatia necessária à sobrevivência. Para alguns jovens, essa situação seria rompida, justamente, pelos atos violentos. Nesse diapasão, Viñar (2009) nos convida a refletir sobre as mudanças que têm ocorrido no campo social e nas subjetividades nas últimas décadas, o que considera um desafio que incita a psicanálise a abrir novas reflexões, especialmente no que concerne aos modos como a juventude tem expressado seu sofrimento.

\section{A escuta extramuros e a ética da psicanálise nas Rodas de Escrita}

Apesar de ter nascido no berço da burguesia vienense, a partir das observações de Freud, no final do século XIX, a psicanálise não se limita apenas a uma parte da sociedade. Propondo uma escuta e um olhar desde outro lugar até então desconhecido, a psicanálise gerou uma revolução no conhecimento ocidental, evocando uma nova posição ao sujeito atravessado pela perspectiva do inconsciente, da sexualidade infantil e da transferência. Desde esses pilares, conforme as palavras de Broide (2010), “a psicanálise é do mundo, de todos os lugares e classes sociais e está onde a vida pulsa" (p. 54).

Recusando a divisão entre indivíduo e sociedade, Freud, ao longo de sua obra, não se furtou em analisar fenômenos coletivos como religião, cultura, arte e guerra. Laplanche (1987) nos fala em psicanálise extramuros, buscando, justamente, romper com a noção de uma psicanálise descoberta na clínica e aplicada a contextos distintos. O autor propõe transpor as barreiras, os muros da clínica, pois a psicanálise também pode ser produzida em outros campos que não somente aquele do tratamento clássico.

Para Freud (1912/2006), é no discurso e na fala livre que se apresentam os restos e fragmentos 
oriundos do inconsciente. Nesse sentido, a regra fundamental da psicanálise é a da livre associação, ou seja: trata-se de convidar o sujeito a falar tudo que lhe vier à mente, a não se censurar, ainda que sinta vontade de fazê-lo.

Em contrapartida, o analista deve escutar os restos que lhes são endereçados partir da atenção flutuante (Freud, 1912/2006). Tal noção remete à questão de uma posição de escuta balizada por não privilegiar qualquer assunto ou tema. Nesse sentido, o analista não deve se antecipar às falas dos sujeitos e seus possíveis sentidos.

A principal ferramenta do método psicanalítico é a transferência. Esse é um conceito proposto por Freud (1914/2006) a partir da percepção de que, em todas as relações cotidianas, o sujeito está fadado a repetir, e, portanto, transferir seus modos de relações com as figuras parentais infantis. Em "Recordar, Repetir e Elaborar”, Freud (1914/2006) refere que, entre analista e analisando, é essencial que se instaure a transferência, motor a fazer engrenar o processo terapêutico. É a transferência que permitirá ainda a revivescência da sexualidade infantil, dessa vez com a figura do analista, condição sine qua non ${ }^{3}$ para a abertura da possibilidade de elaboração e criação de outras rotas para a libido. Para Elia (1999), é possível estender esse conceito para a relação pesquisador-psicanalista e sujeito-participante, já que o pesquisador está diretamente implicado no processo em si, junto aos sujeitos de pesquisa, instaurando-se, assim, os fenômenos transferenciais.

Para Elia (2000), toda pesquisa psicanalítica é também uma pesquisa clínica por ser a clínica a via de acesso ao sujeito do inconsciente. Nesse sentido, ele refere que é preciso que o pesquisador empreenda sua investigação a partir do lugar de analista, de um lugar de escuta, que não deixa de pressupor o desejo do analista. Entendemos, assim, que a escuta psicanalítica pode se dar em qualquer contexto, não somente na clínica tradicional, desde que se resguardem os pressupostos fundamentais da psicanálise - ou seja, sua ética. Os princípios norteadores da psicanálise extramuros constituem um campo de experiência no qual fundamentos e metodologia são os mesmos que sustentam a ética psicanalítica (Rosa \& Domingues, 2010).
Para sustentar nossa metodologia, também buscamos o seminário 7 de Lacan (1959-60/2008), intitulado "A Ética da Psicanálise". Nesse seminário, o psicanalista traça a ética do bem-dizer, buscando diferi-la da ética do Bem Supremo proposta por Aristóteles (Gurski \& Strzykalski, 2018a). A ética do bem-dizer deve orientar a posição do psicanalista em direção à ascensão do sujeito, buscando fazer um contraponto à moral do bem supremo aristotélico. Essa diferenciação que propõe Lacan (1959-1960/2008) é fundamental para sustentar a posição do psicanalista, seja na clínica ou no extramuros 4 .

A ética convocada por Lacan (1959-1960/2008), que sustenta nossa posição, é aquela que se propõe a uma escuta do sujeito e de sua singularidade. Desse modo, enquanto na clínica tradicional a escuta do psicanalista implica que ele passe a ocupar uma posição de suposto saber junto ao sujeito, nos contextos extramuros haveria uma inversão desse modelo, sendo o pesquisador-psicanalista aquele que supõe que o sujeito saiba algo. Assim, seria necessário ao pesquisador colocar-se de modo a deixar com que o sujeito encontre e formule suas próprias questões, respondendo a elas na transferência, em seu tempo singular (Rosa \& Domingues, 2010).

Além dos pressupostos psicanalíticos, a construção do projeto das Rodas de Escrita foi amparada pela importante contribuição de Walter Benjamin (1936/2012) acerca do tema da experiência. Com o advento da modernidade, a individualidade e as narrativas anônimas passaram a ganhar espaço em detrimento das experiências compartilhadas, quando o narrador contava e "esquecia de si, pois não era autor no sentido egóico, ele era um elo a mais na cadeia da transmissão" (Gurski, 2008, p. 186). Desse modo, Benjamin (1936/2012) apontou o surgimento da Erlebnis, que corresponde ao que o autor denomina como a simples vivência do sujeito isolado, vivente do instantâneo, em contraponto à experiência compartilhada, rica em laços e tecida por meio da transmissão (Gurski, 2008, 2012).

Para Benjamin (1936/2012), o terreno da vivência remete à experiência interior, empobrecida de laços culturais, valorizando o vivido individualmente em detrimento do coletivo. Encontramos intersecções

\footnotetext{
${ }^{3}$ Do latim, em tradução livre: indispensável, essencial.

${ }^{4}$ Para outros detalhes acerca do tema da ética na pesquisa psicanalítica com socioeducação, ver "A escuta psicanalítica de adolescentes em conflito com a lei: que ética pode sustentar esta intervenção?” (Gurski \& Strzykalski, 2018).
} 
dos apontamentos de Benjamin (1936/2012) em nossa experiência no campo socioeducativo: percebemos que a passagem dos jovens pelas internações reduzem-se, muitas vezes, a uma simples vivência - são atividades de estudos, de profissionalização, um "corre-corre" em qual a palavra e as histórias de cada um parecem se perder. Nesses espaços, as experiências de transmissão, aquelas potentes para a construção de laços com o social, são, aparentemente, escassas.

Acreditamos que a construção de experiências, e não apenas a "pilhagem de vivências" (Gurski \& Strzykalski, 2018a, p. 412), constituem um modo de tessitura de traços identitários que suportam o sujeito nas diferentes representações de si no laço social. Dessa forma, a criação de dispositivos que trabalhem a partir das narrativas do sujeito, faladas ou escritas, como as Rodas de Escrita propostas nesta pesquisa-intervenção, podem ser formas de ofertar algumas condições de transformação dessa passagem dos jovens pelas internações em privação de liberdade. Podem também vir a oferecer, a partir disso, a possibilidade de produção de deslocamentos nos modos de representação no laço social.

\section{Escrevendo por entre muros e paredes: as Rodas de Escrita}

Durante quatro meses, as Rodas aconteciam semanalmente por meio de encontros com 2 horas de duração em uma sala da instituição socioeducativa. O grupo era constituído pela pesquisadora e por sete adolescentes $^{5}$ entre 14 e 18 anos de idade que aceitaram participar do projeto de maneira espontânea. Cabe dizer ainda que, a partir do que escutamos deles, tratavam-se de jovens advindos de diferentes contextos de violência e vulnerabilidade.

A dinâmica das Rodas dividia-se em dois momentos: o primeiro era reservado a uma conversa livre em que cada um poderia fazer uso da palavra como desejasse. A partir disso, surgia, geralmente, um tema disparador para alguma produção escrita, podendo ela ser coletiva ou individual. Optamos por ofertar-lhes um caderno, como uma espécie de diário, a fim de que pudessem seguir registrando seus sentimentos mesmo quando não estivéssemos reunidos; eles podiam ou não compartilhar conosco tais escritas.
Ao final de cada encontro, a pesquisadora também escrevia anotações livres acerca das impressões, sensações e percepções por meio dos diários de experiência (Zachello, Paul \& Gurski, 2015; Gurski, 2017, 2019; Gurski \& Strzykalski, 2018a). Segundo Gurski (2017), os diários de experiência são anotações norteadas pela associação livre da pesquisadora, aproximando-se muitas vezes de um texto fragmentado ou desarticulado. A construção dos diários foi inspirada em três fontes:

nos diários de campo, dispositivo advindo dos estudos antropológicos e da etnografia; nos cadernos de notas e comentários breves de Walter Benjamin (Arendt, 1987), guiados por "seu olhar fragmentário, não por renunciar à totalidade, mas por procurá-la nos detalhes quase invisíveis" (Sarlo, 2013, p. 35) e por fim, nas chamadas crônicas breves escritas por Freud (2004) entre os anos de 1929-1939 (Gurski, 2017).

Em suma, o corpus da pesquisa que dá origem ao presente artigo é composto tanto pelos escritos produzidos pelos adolescentes quanto pelos diários de experiência da pesquisadora que conduziu as Rodas. O operador que orientou a análise desses materiais, bem como o trato com os textos teóricos, foi a leitura-escuta (Caon, 1994), ou seja, privilegiou-se uma leitura dirigida pela escuta em atenção flutuante dos textos e materiais reunidos sobre a temática a ser estudada.

Nos primeiros encontros das Rodas de Escrita, os sete adolescentes participantes estavam um tanto tímidos e desconfiados em relação à pesquisadora: "o que tu veio fazer aqui? Por que quer saber o que a gente pensa?". Mostravam-se também a partir dos códigos penais análogos aos delitos pelos quais cumpriam as medidas: "122" e "177" estampavam as folhas e capas dos cadernos. Ainda, apresentavam-se com as posturas que costumavam adotar nas ruas, como "o patrão", "o cara", ou, como referiu o jovem F., "até a polícia tinha medo de mim, eu tava grandão".

Conforme ia sendo transmitida uma posição de escuta, foi também se estabelecendo a transferência: queriam saber de onde vinha a pesquisadora, o que queria fazer ali, de que cidade era, entre outras dúvidas. Ao refletirmos sobre esse complexo

\footnotetext{
${ }^{5}$ A fim de garantir o anonimato dos jovens, modificaremos seus nomes por A., S., M., D., C., R. e P.
} 
processo que é a transferência, pensamos em como ele se daria em contextos que fogem ao padrão da clínica tradicional - na ausência do divã e sem a privacidade do consultório. Esse impasse surgiu em uma cena da pesquisa:

A. é o que mais fala, pergunta se faço esse trabalho em outra unidade e diz que acha que eu deveria fazer, que os outros também tem que ter isso, que seria bom pra todos. Depois pergunta o que os meus amigos pensam de eu estar ali, pergunta se atendo em consultório, e diz que imagina que devo cobrar muito caro (Fragmentos dos diários de experiência da pesquisadora).

Desprendidas da pretensão de trabalhar as questões transferenciais como na clínica, mas dispostas a trabalhar tal como nos permitiria o tempo e o espaço que a realidade daquele contexto impunha-nos, atentamos para a construção dos laços entre participantes e pesquisadora. Para Rassial (2005), no encontro com o adolescente, a questão de saber desde onde o analista fala ou se cala é fundamental. Inicialmente, conforme o autor, o adolescente fará esforços para colocar o analista em uma posição de adulto desvalido, movimento que levaria ao fracasso qualquer tipo de tratamento. Rassial (2005) refere ainda os riscos que o analista assume ao ocupar uma posição de cúmplice ou de mestre, detentor de saber e verdade.

A partir das referidas falas dos jovens, também pensamos acerca da extrema falta de confiança deles com os adultos em geral, o que nos conduziu a questionarmos como o Outro ${ }^{6}$ tem se apresentado para eles: o laço social parece não fornecer condições passíveis de construção de um lugar de fala para esses jovens, não ofertando meios que permitam a circulação da palavra. É como se dissessem: "que valor tem o que eu digo ou penso?", ou ainda, "por que se interessa por mim?". Aqui podemos vislumbrar a ideia que propõe Agamben (2010) quando nos fala sobre o homo sacer, sobre os sujeitos à margem da sociedade, ocupando um lugar de resto no laço social.

Com o passar dos encontros, foram surgindo falas por meio das quais notamos que os laços estavam se tornando mais consistentes entre pesquisadora e adolescentes: "Gosto de vir aqui, aqui a gente pode falar das coisas. Não consigo conversar com quase ninguém, mas aqui eu até que falo", disse $S$. Ou ainda: "A dona parece que entra na cabeça do cara, a gente acaba falando os bagulhos", disse $\mathrm{D}$.

Percebemos que uma preocupação bastante presente, especialmente no início das Rodas, se dava acerca do "certo e errado": perguntavam constantemente se deviam ou não escrever de tal jeito, o que deveriam fazer, como se devessem encaixar-se em um determinado modo de ser ou fazer. Pareciam buscar na pesquisadora uma posição de mestre, detentora de respostas, como refere Rassial (2005). Buscando contemplar justamente a possibilidade da livre expressão dos meninos, surgiu este momento:

Os guris começam a dizer que tinham a letra feia, que eu não ia entender os escritos deles. Fui dizendo que não era importante a letra ser bonita, e sim o que eles tinham a dizer. Pediram então que eu escrevesse com minha letra, o que fiz, e, para surpresa dos meninos, minha letra era bastante incompreensível. Eles não conseguiram entender e acharam engraçado. (Fragmento dos diários de experiência da pesquisadora)

Nessa situação, ficamos com a impressão de ter transmitido, desde a escrita de uma letra incompreensível, a abertura de um espaço em que os adolescentes poderiam mostrar também suas linhas tortas, seus garranchos. Notamos que eles, a partir deste encontro, passaram a dizer uns aos outros, quando alguém receava estar escrevendo errado, algo como disse M.: "não te preocupa, meu ... não tem problema se não estiver bonito, faz o bagulho do teu jeito". Talvez neste momento tenha sido possível transmitir aos adolescentes que não eram necessárias explicações, certezas, certo e errado. Que eram eles que contariam sobre si mesmos e não a pesquisadora. A palavra era deles! Um trecho da história produzida ao longo do encontro mencionado foi o seguinte: "Era uma vez um omem na estrada que pensava em viajar o mundo inteiro, por que não tinha muita liberdade, porque era de pais ricos, ele não conseguia faze nada para ser feliz" (Escritos de R. e C.).

Por meio dessas e outras cenas, passamos a pensar que a criação de espaços nos quais os jovens possam

${ }^{6}$ Outro: instância simbólica, da linguagem, que determina o sujeito. É de natureza anterior e exterior ao sujeito. Ver mais em Lacan (1954-55). 
ter suas escritas, seus modos de expressão reconhecidos, torna-se uma ferramenta importante de trabalho. Lange (2010), ao escrever sobre uma experiência de oficina de escrita com os adolescentes, sustenta que a escrita e a leitura funcionam como suportes para a construção de um lugar de criação e enunciação.

\section{Escrevendo "o que vem na mente": Deslizando da vida nua, vida loka, a vida loka tb ama}

Nas primeiras semanas, observamos que era necessário retomar constantemente a proposta da fala livre. Os meninos, muitas vezes, pareciam aguardar que fosse dada uma ordem ou direção sobre o que deveriam fazer, provavelmente devido à associação que ainda faziam entre a pesquisadora e o sistema socioeducativo, em que existem normas e regras bastante estabelecidas. A. movimentava as Rodas ao dizer para os demais participantes: "escreve o que vier na mente, cara!". Com a caneta e o papel na mão, através das reticências, ia nos permitindo conhecer o que lhe passava: "Liberdade... saudades a mil... amor é só de mãe... só deus pode me julgar" (Escritos do A.).

Com o girar das Rodas, os meninos começavam a chegar aos encontros e tomar o lápis e o papel nas mãos para, logo em seguida, escrever "o que vem na mente". No só depois da experiência, fomos entendendo como esse movimento fazia surgir a dimensão da vida loka: as vivências nas ruas, as revoltas, a relação com o crime, as insatisfações, sentimentos e amores.

Também percebemos que os adolescentes faziam uso dos cadernos, escrevendo durante os dias que se passavam entre um encontro e outro das Rodas. Um dos adolescentes pareceu descobrir nesse espaço um interlocutor. A. disse: "Não consigo dormir, dona, a cabeça não para, dona. Tento dormir, mas não consigo. Sempre que eu precisar vou escrever tudo aqui, vou escrever todo dia" (Fragmento dos diários de experiência da pesquisadora).

O adolescente alternava sua frequência nas Rodas de Escrita com a participação em outra atividade artística que ocorria no mesmo horário. Certa vez, ao cruzar com a pesquisadora nos corredores da instituição, acenou e enunciou sem que lhe fosse perguntado: "estou escrevendo, dona! Semana que vem, pinto lá!". Com 16 anos e cumprindo medida por tráfico e homicídio, A. compartilhou nas Rodas o modo como pensava em solucionar o mal-estar que sentia: "hoje eu acordei com muito ódio, dona, gostaria de torturar alguém, algum inimigo, sou um cara de agir, não um cara de pensar".

Em outro encontro, ele trouxe este escrito:

Hoje eu me acordei no ódio. Hoje me deu saudade de $v c$, mas do que adianta eu $t a$ com saudades de você e tu nem aí? Dia de caça e do caçador. Naquele mundo de gostosa, eu só tinha mulher boa. Hoje quem me fas visita é só minha coroua. Só quero sai daqui e jamais me vingar (Escritos do A.).

Misturando seus escritos autorais com trechos de músicas, A. nos transmite a impressão de ter criado um modo próprio de expressar, por meio da escrita, as tramas em que se encontrava. Transitava entre o desejo de vingança, "dia de caça e do caçador", e o de "jamais me vingar". Costa (2001) refere a escrita como um ato criativo e como um potente operador na subjetividade do sujeito, uma saída para a construção de um sintoma singular.

Nas escritas dos diários, bem como as realizadas durante os encontros, fomos vendo surgirem escritos como os de M.: "não vou proibir meu filho de fumar maconha e beber com amigos por que não adianta. Minha mãe me proibia e olha onde eu fui parar... expresando meus sentimentos numa folha" (Escritos do M.).

Neste trecho do diário de M., o adolescente enlaça passado e presente, revendo sua trajetória e realizando uma reflexão acerca de sua relação com a mãe, bem com uma certa reflexão acerca de seu envolvimento com o mundo do crime: "eu gostava de contrariar". Ao escrever "não vou proibir meu filho de fumar...", M. parece bordejar o futuro e a escrita de um outro romance familiar. Aos poucos, fomos percebendo os jovens questionando e falando de suas participações nos delitos, bem como, por vezes, buscando encontrar saídas para não reincidirem nos atos infracionais.

Conforme as escritas dos adolescentes e a partir das assertivas de Lima (2014), reconhecemos que a escrita do caderno-diário e seu compartilhamento nas Rodas parecia abrir espaço para novos lugares, para novas questões, como as palavras de A. nos fazem pensar: "vida loka - tava alembrando do pasado. Cadê minino bonsinho :(?” (Escritos do A.).

Questionando-se acerca de seu escrito sobre o "menino bonzinho", modo como a mãe lhe chamava quando criança, A. enrubesceu e emocionou-se. Olhou para os demais meninos e para a pesquisadora como que esperando uma resposta: "Onde foi parar?". 
Com uma certa nostalgia, relembrou alguns momentos da infância e a proximidade com a mãe: "minha corôa chora, se sente culpada pela vida que nóis leva. Mas não é culpa dela não. Mas ela é uma mãe, as mães são assim" revela.

Entre este "ir e vir", como um jogo de carretel, entendemos que os adolescentes esboçaram, por meio da escrita no caderno-diário, outras versões de suas histórias. Encontrando nas Rodas um espaço para reescreverem suas trajetórias, as páginas foram sendo escritas, servindo também como costuras entre adolescentes e pesquisadora - ou ainda como um elo entre as Rodas e os adolescentes. Uma situação que nos levou a pensar nisto se deu após o quarto ou quinto encontro, quando as atividades foram suspensas por cerca de um mês devido a questões institucionais. Ao retomarmos os encontros, escutamos dos adolescentes frases tais como a dita por S.: "Achei que tinha esquecido da gente, dona. Mas eu segui escrevendo no diário".

Notamos que os adolescentes seguiram enlaçados com as Rodas por meio da escrita no caderno-diário, material que permaneceu com eles no período de nosso afastamento. Essa função seguiu se cumprindo ao longo das semanas que separaram um encontro e outro. A materialidade da escrita e do diário parece ter sustentado os laços transferenciais que vinham se estabelecendo entre adolescentes e pesquisadora, que propiciavam a aposta deles na escrita como modo de dizer de si.

Outra importante marca nas Rodas foi a presença constante dos escritos das paredes dos dormitórios, uma das fontes inspiradoras para construção do projeto de pesquisa durante os encontros. Ao conversarmos a respeito desses escritos, R. referia: "a gente sabe que não pode, mas a gente escreve, sempre consegue uma caneta né, dona. O cara fica lá, sem nada prafazer, muita coisa na cabeça, daí a gente escreve". Sobre esses dizeres de R., poderíamos pensar na escrita como uma forma de escoar "muita coisa na cabeça", além de ser um modo encontrado pelos adolescentes de se fazer visíveis na instituição - afinal, como não enxergar as letras garrafais, coloridas, que vão do chão ao teto?

Observamos que os adolescentes traziam o que escreviam nas paredes para os cadernos-diários e para circular nas Rodas. Eram frases autorais e também escritas por jovens anteriormente internados. Escutamos esse movimento de maneira atenta, pois ia ao encontro de nossa percepção inicial de que algo estava sendo comunicando através das paredes e precisava ser escutado. Passamos também a perceber que a escolha dos jovens em copiar as frases tinha relação com suas identificações, assim como com os conteúdos presentes nos escritos realizados por outros jovens, funcionando enquanto uma forma de contar-se por meio da palavra emprestada por um outro adolescente: "Às vezes, um cara como eu quer ser alguém na vida. Quer plantar sua semente e colhe o fruto certo. Pensar antes de agir é derrubar o mal" (Escrito das paredes dos dormitórios trazido por D.).

Como um legado, essa espécie de transmissão de um saber, um saber da vida loka, transmite-se pelas paredes, de um adolescente para o outro. É como se tantos jovens autores que já se foram pudessem seguir presentes na medida em que emprestam suas palavras aos que chegam. Esses, por sua vez, parecem reconhecer, no concreto que os cerca, um espaço para criar, responsabilizar-se e resistir ao silenciamento, um espaço para criar uma outra posição frente ao Outro.

Reescrever os modos de se inscrever no laço social, que se traduzem pela busca por um lugar de legitimidade, de um nome para o gozo, continua sendo a tarefa central da adolescência contemporânea (Guerra, 2017). Conforme Lacadée (2012), para alguns sujeitos, tal tarefa torna-se um risco na medida em que, ao se encontrarem com um "excesso de gozo que invade seu corpo" (p. 59), um excesso que não encontra aporte no laço social, esses jovens podem acabar optando pelo que o autor nomeia de "errância verbal ou física" (p. 59), cuja forma de apresentação pode ser por meio dos atos infracionais. Lacadée (2012) trabalha com a noção de que, na adolescência, se daria uma "crise na linguagem", pois o jovem não encontra mais abrigo no discurso do Outro, como se passava na infância, rejeitando, desse modo, o discurso e o saber que consentia no passado (Lacadée, 2012).

Deste impasse entre linguagens, surge para o adolescente a tarefa de "encontrar uma língua para dizer sobre si ao Outro" (Lacadée, 2012, p. 261). Nos meandros do desacordo, o jovem acaba por ser lançado no vazio, ficando à mercê de certa instabilidade linguageira. $\mathrm{O}$ autor segue:

A passagem ao ato ou a uma prática de ruptura condena o sujeito a uma errância, longe de qualquer inscrição significante que possa ancorá-lo no campo do Outro. O ato serve, então, às vezes, como modo de saída ao impasse da relação com o Outro, ao que é experimentado a partir de um impossível a dizer (Lacadée, 2012, p. 263). 
Ante esse "impossível de dizer", Lacadée (2012) refere que, por vezes, o adolescente vai fazer-se nomear como "psicopata" ou "toxicômano". Nesse contexto, também podemos pensar em como os adolescentes que passam pela socioeducação costumam nomear-se pelos códigos penais análogos aos delitos cometidos, tendo esses números inscritos em tatuagens, nas folhas em que escrevem durante as Rodas e presentes pelas paredes dos dormitórios.

Ao darmos início à convivência com os adolescentes participantes da pesquisa, antes mesmo das Rodas de Escrita iniciarem, percebemos que uma das formas muito presentes de se apresentarem tinha relação com os atos infracionais cometidos: pareciam preocupar-se em demonstrar força e malandragem, enunciando os códigos penais pelos quais cumpriam medida. Era como se, conforme já referido por Lacadée (2012), ante ao impasse em se fazer representar, na impossibilidade de ancorar-se no Outro, os adolescentes se apropriassem dos "papéis de traficante", dos "títulos" da vida loka, e passassem a contar suas histórias desses pontos de partida.

Este modo de se apresentar, ou seja, essa forma de se contar ao mundo - por meio dos delitos - apareceu desde os escritos pelos muros e paredes até os escritos nas Rodas e nos cadernos-diários. Nos encontros iniciais, enquanto as capas dos cadernos eram confeccionadas, os códigos se apresentavam em letras destacadas. Nas falas, circulavam os significantes da malandragem, da ousadia das ruas, das gírias do mundo do crime. "Sou patrão da quebrada" e "tô grandão" foram frases que escutamos com frequência e que pareciam, muitas vezes, querer mostrar quem era o mais temido dentre eles:

O P. uma vez tacou fogo num carro com um pedreiro dentro. Deu uns tiro no cara por vingança, ele e mais uns mano. Os caras viviam se crescendo pra cima da gente quando tava de patrão. Daí eles aproveitaram pra se vingar, meteram bala nele, tacaram fogo (Fragmento dos diários de experiência da pesquisadora).

Lacadée (2012) refere que o encontro com o real vivido na adolescência faz com que a angústia, o tédio, a solidão e também a agressividade ocupem um primeiro plano, sendo esses sentimentos vividos de forma ainda mais aguda quando os jovens residem em regiões periféricas, onde o laço social oferta um número menor de oportunidades em vários sentidos de lazer, educação, saúde, cultura e outros.

Desse modo, somos levados a crer que o ingresso no mundo do crime poderia ter relação com um modo de se fazer representar no social, uma maneira de nomear o impasse em relação ao Outro ao ingressar na linguagem (laço social) por meio do ato. É o ato que poderia então transmitir (e encontrar) um lugar para o adolescente errante ante o impasse da busca por outro modo de se fazer representar.

Assim, poderíamos pensar que, na periferia, os adolescentes seriam convocados intensamente a responder às angústias de reconhecimento por meio, por exemplo, do envolvimento com atos infracionais. Nesse sentido, temos de considerar o papel desempenhado pelos traficantes em suas comunidades, trazendo para esses espaços, muitas vezes, certos benefícios que o Estado falha em fornecer. Ou seja: o chefe do tráfico pode apresentar-se como um modelo a ser seguido pelos jovens. Os adolescentes desejam ser "patrão", carregando o código do delito inscrito na pele e também no nome: "M. 157, 121", conforme costumava assinar um jovem ao final de seus escritos nas Rodas.

Aos poucos, os adolescentes passaram a discutir a respeito de suas entradas para o crime, sobre os problemas familiares, tendo sido referido por alguns deles que as dificuldades da vida, especialmente relacionadas à questões financeiras, seriam os motivos que os levaram a começar a traficar: "ah, a gente quer sustentar a família, quer comprar coisas boas", referiu R. "Ah, a gente sai no mundão e fica louco, quer as coisas, daí a gente quando vê, fica difícil não fazer", disse M.

Tivemos a impressão que os escritos e falas que circularam nas Rodas foram propiciando um certo afrouxamento nos saberes que se apresentavam como totais aos jovens participantes e que lhes asseguravam um lugar, um modo de se fazer representar no laço social: "Amor é só de mãe!!! Eu não sei o que é amor de verdade. Eu só fiz maldade, por isso que eu não sei o que é amor de verdade. Vida loka tb ama" (Escritos do A.).

Entre a "maldade" e a figura maciça de "patrão", passou a surgir a dúvida - "não sei o que é o amor de verdade" - e a afirmativa - "vida loka $t^{7}$ ama". Dentre a mistura paradoxal de percepções a respeito de si próprio, parece ressoar um desejo de ser visto não

${ }^{7}$ Tb: abreviatura da palavra também. 
somente como alguém capaz de fazer "só" maldade, mas de como alguém capaz de amar. A. é um exemplo de quem parece deslizar brevemente do significante o "amor" que "é só de mãe" e o "menino bonzinho" para a vida loka, para o "mundão" do crime.

Parecendo buscar outro nome, A. também demonstrou bastante curiosidade quanto ao destino das escritas realizadas nas Rodas, perguntando, várias vezes, quem teria acesso a elas e o que se produziria a partir de nossos encontros. Na ocasião, a pesquisadora explicou novamente que seria produzido um trabalho a partir daquela experiência, e que este trabalho poderia inspirar outros pesquisadores a desenvolverem projetos semelhantes em outras instituições. A. pareceu motivar-se com este fato, com a possibilidade de ser "lido" por outras pessoas. Para esse jovem, expressar-se por meio das palavras escritas, que seriam então lidas, conforme suas palavras, "pelo pessoal da UFRGS", parecia apresentar-se como uma possibilidade de ser visto diferente, de mostrar um "outro lado" para além de "traficante", "vagabundo". Seria um jeito de mostrar que "vida loka tb ama"?

Retornando aos escritos, consideramos importante um momento em que, a partir de um trecho produzido por A., foi possível perceber movimentos interessantes nas falas do grupo. Inspirado em suas escritas sobre deixar o crime, ele diz:

Uma vez, eu fui atrás de um cara que traficava pra nós, ele quis sair, mas não é assim não! E ele tinha entrado praigreja, mas né... Peguei ele, e pá, atirei nele ali mesmo, já era. Daí depois vim parar aqui. A. me olha pensativo e diz: "é complicado né, dona, porque eu mesmo já fiz isso, de não deixar as pessoas sair. E agora eu tô aqui pensando que eu quero sair. Como é que eu faço, né?" (Fragmento dos diários de experiência da pesquisadora).

Neste fragmento, podemos perceber que o adolescente, a partir do diálogo despertado pela escrita do grupo durante as Rodas, encontra-se com dois lados de si mesmo: de algoz, que mata o ex-parceiro de tráfico por ter deixado o crime, mas também de vítima no momento em que refere querer trabalhar, mas que teme ser morto se fizer tal tentativa. Pareceu ter se instaurado uma nuance de conflito em A., um espaço para o pensamento, a partir da reflexão sobre sua posição passada e atual. Também percebemos estes movimentos surgirem em M: "Vou sair desse lugar mudado porque não quero essa vida (loka) pro meu filho" (Escritos do M.).

Apareciam também, para além do 157, os sonhos de uma vida diferente da vida loka, longe do crime. Uma vida colocada em dúvida a todo momento, como expressa A., mas que foi possível vislumbrar após poucos encontros; deslizar para sonhar. Foi com a proximidade do final de nossos encontros que D. também sonhou e escreveu: "Eu sonhei com a minha namorada, eu sonhei que quando saísse daqui eu ia me casar com ela e levar ela para minha casa ter a minha família" (Escritos do D.).

\section{Considerações finais}

A partir da experiência com as Rodas de Escrita, pensamos que os fundamentos psicanalíticos e suas costuras com o tema da experiência são ferramentas potentes para que os jovens possam vir a fazer outros enlaces com o laço social que não somente por meio do ato infracional. Nesse sentido, salientamos a importância de que se ofereçam espaços de escuta dos discursos que eles têm produzido sobre si próprios e sobre o mundo. Como vimos, tais narrativas se apresentam não apenas na oralidade, mas também nas múltiplas escritas dos muros e paredes da instituição.

Entendemos, desde Lacan (1954-1955/1985), que o sujeito se constitui a partir do discurso do Outro. É precisamente a partir dessas narrativas que o sujeito encontra seus modos de se reconhecer e de se apresentar no laço social. No caso dos adolescentes das Rodas, percebemos que é frequente que eles se apresentem justamente como delinquentes - não como um dos significantes que os constituem, mas como algo que daria conta de dizer deles em uma certa totalidade. Nesse contexto, entendemos que o psicanalista poderia, pela via da transferência, escutar e sustentar um espaço em que seja possível fazer deslizar os significantes relacionados à vida no crime.

Em “O mal-estar na cultura”, Freud (1930/2006) refere que aquilo que o plano do princípio do prazer nos impõe - atingir uma satisfação plena, a felicidade - não é possível de ser atingido, sendo um dos maiores empecilhos para tal realização o próprio semelhante. No cenário público, nas margens, percebemos que essa afirmativa mostra sua versão mais crua, como temos visto e discorrido ao longo deste trabalho. Todavia, mesmo diante das memórias da guerra, e frente a um futuro trágico por vir, Freud (1930/2006) também anunciava que não devemos 
abrir mão do esforço para o encontro com aquilo que ele nomeia como felicidade.

Ainda que possamos compreender a falta de condições e a aridez presentes no trabalho realizado nas instituições socioeducativas, o que ocorre, mesmo que com algumas exceções, são certas reproduções da lógica e do discurso contemporâneo. Isto é, da manutenção do adolescente em um lugar de resto, espelhado pelos nomes-rótulos da delinquência e da vida loka do crime. Nesse ponto é que a ética psicanalítica à contrapelo dessa lógica pode operar aproximando o sujeito à verdade de seu desejo, possibilitando uma maior abertura para que se construam outros sentidos para a existência.

Nessa direção, reiteramos a aposta na psicanálise e em dispositivos como as Rodas de Escrita. É necessário ser criativo dentro desse campo para não correr o risco de permanecer no lugar da impotência (Gurski \& Strzykalski, 2018b) que contextos como o da socioeducação provocam: os recursos são escassos, o número de profissionais é pequeno e o ambiente em si é pesado e sombrio. Desse modo, é preciso que o pesquisador-psicanalista possa, no contrafluxo da rotina institucional, escutar a palavra que vem em forma de gíria, dançar a música que vem em forma de RAP e ler a palavra grafitada nas paredes. É a partir dessa posição ética de escutar as diferentes formas de expressão dos sujeitos que apostamos na potência da psicanálise enquanto propulsora de modos não só de resistir, mas também de construir e contribuir para um revigoramento das formas de fazer a socioeducação.
Percebemos que foi possível tomar as escritas nas paredes não apenas como uma espécie de infração a ser corrigida, mas, sim, como um modo encontrado pelos jovens de fazer falar suas passagens pela instituição, suas experiências de vida, sonhos e angústias. Também pudemos ver as palavras saltarem das paredes e dos muros ao papel, tomarem voz, encontrando, na experiência compartilhada, tempo para produzir questões, para quebrar certezas, para criar, para sonhar, e para fazer deslizar a vida nua, encontrando outros e novos sentidos para a vida loka: vida-loka-tb-ama!

Poderíamos dizer que a psicanálise se ocupa em ressignificar, em despertar outros sentidos frente ao traumático e à destruição. Levando sua ética, por entre os muros e paredes de uma instituição socioeducativa, entendemos que a escuta dos sujeitos pode constituir um modo de resistência, uma forma de não sucumbir, apesar do cinza, dia após dia, Roda após Roda, às repetições de exclusão, de apagamento dos sujeitos e de destruição. Afinal, em uma instituição com tantas ambiguidades, com tantos paradoxos, também vimos surgir a vida em forma de letra, nos muros e paredes, em forma de rima, em forma das trocas e laços que fizemos com os adolescentes e com alguns membros da equipe que já resistiam, questionando seu fazer diário em busca de alguma espécie de novo. Cremos nesses laços feitos e também nas futuras construções que possam advir por meio da aposta na circulação da palavra e em espaços que privilegiam as produções dos sujeitos, por esses e tantos outros muros e paredes.

\section{Referências}

Agamben, G. (2010). Homo Sacer: O poder soberano e a vida nua I (2a ed.). Belo Horizonte, MG: Editora UFMG.

Arendt, H. (1987). Homens em tempos sombrios. São Paulo, SP: Companhia das Letras.

Benjamin, W. (2012). O Narrador: Considerações sobre a obra de Nikolai Leskov. InW. Benjamin, Obras escolhidas: Magia, técnica, arte e política (Vol. 1, 8a ed., pp. 213-240). São Paulo, SP: Brasiliense. (Trabalho original publicado em 1936)

Broide, J. (2010). Psicanálise: Nas situações sociais críticas. Violência, juventude e periferia: Em uma abordagem grupal. Curitiba, PR: Juruá.

Caon, J. L. (1994). O pesquisador psicanalítico e a situação psicanalítica de pesquisa. Psicologia: Reflexão e Crítica, $7(2), 145-174$.

Costa, A. (2001). Corpo e escrita: Relações entre memória e transmissão da experiência. Rio de Janeiro, RJ: Relume Dumará.

Elia, L. (1999). A transferência na pesquisa em psicanálise: lugar ou excesso? Psicologia: Reflexão e Crítica, 12(3). http://www.scielo.br/scielo.php?script=sci_arttext \&pid=S0102-79721999000300015 \&lng=pt \&nrm=iso \&tlng=pt

Elia, L. (2000). Psicanálise: clínica e pesquisa. In S. Alberti, \& L. Elia, Clínica e pesquisa em psicanálise (pp. 19-35). Rio de Janeiro, RJ: Marca D’Água. 
Freud, S. (2004). Diário de Sigmund Freud: 1929-1939. Crônicas Breves. Porto Alegre, RS: Artmed.

Freud, S. (2006). Mal-estar na civilização. In Edição standard brasileira das obras psicológicas completas de Sigmund Freud (J. Salomão, Trad., Vol. 21, pp. 67-150). Rio de Janeiro, RJ: Imago. (Trabalho original publicado em 1930)

Freud, S. (2006). Recomendações aos médicos que exercem a psicanálise. In Edição standard brasileira das obras psicológicas completas de Sigmund Freud (J. Salomão, Trad., Vol. 12, pp. 122-136). Rio de Janeiro, RJ: Imago. (Trabalho original publicado em 1912)

Freud, S. (2006). Recordar, repetir e elaborar (Novas recomendações sobre a técnica da Psicanálise II). In Edição standard brasileira das obras psicológicas completas de Sigmund Freud (J. Salomão, Trad., Vol. 12, pp. 161-174). Rio de Janeiro, RJ: Imago. (Trabalho original publicado em 1914)

Guerra, A. M. C. (2017). Como viver junto com a diversidade de gozos? In M. R. Pereira (Org). Os sintomas na educação de hoje: que fazemos com "isso"? (pp. 113-122). Belo Horizonte, MG: Scriptum.

Gurski, R., \& Strzykalski, S. (2018a). A pesquisa em psicanálise e o "catador de restos": enlaces metodológicos. Revista Ágora: Estudos em Teoria Psicanalítica, 21, 406-415. http://www.scielo.br/scielo. php?script=sci_arttext \&pid=S1516-14982018000300406

Gurski, R., \& Strzykalski, S. (2018b). A escuta psicanalítica de adolescentes em conflito com a lei - que ética pode sustentar esta intervenção?. Revista Tempo Psicanalítico, 50, 72-98. http://pepsic.bvsalud.org/scielo. php?script=sci_arttext \&pid=S0101-48382018000100005

Gurski, R., \& Strzykalski, S. (2018c). A 'Invencionática' na pesquisa em psicanálise com adolescentes em contextos de violência e vulnerabilidade: narrando uma trajetória de pesquisa. In: K. Tarouquella, S. Conte, \& D. Drieu (Orgs.). Proteção à infância e à adolescência: intervenções clínicas, educativas e socioculturais. Brasília, DF: Cátedra Unesco de Juventude, Educação e Sociedade.

Gurski, R. (2008). Juventude e paixão pelo real: problematizações sobre experiência e transmissão no laço social atual. (Tese de Doutorado). Universidade Federal do Rio Grande do Sul, Porto Alegre.

Gurski, R. (2012). Três ensaios sobre juventude e violência. São Paulo, SP: Escuta.

Gurski, R. (2019). A escuta-flânerie como efeito ético-metodológico do encontro entre Psicanálise e socioeducação. Revista Tempo Psicanalítico, 51(2), 166-194.

Gurski, R., Strzykalski, S., \& Rosa, M. D. (no prelo). A ética como método no encontro entre psicanálise e socioeducação. Arquivos Brasileiros de Psicologia.

Lacadée, P. (2011). A clínica da língua e do ato nos adolescentes. Responsabilidades, 1(2), 253-268. www8.tjmg.jus.br/ presidencia/programanovosrumos/pai_pj/revista/edicao02/7.pdf

Lacan, J. (1985). O seminário, livro 2: O eu na teoria de Freud e na técnica da psicanálise, 1954-1955. Rio de Janeiro, RJ: Zahar.

Lacan, J. (2008). O seminário, livro 7: A ética da psicanálise, 1959-1960. Rio de Janeiro, RJ: Zahar.

Lange, M. B. (2010). À parte (d)o fogo: Perda e memória. In M. B. Lange, R. I. Bergamaschi, A. M. M. Costa, B. F. Guimarães, S. Scotti, R. Stobbe, \& R. Vargas (Orgs.), Escrita e psicanálise II (pp. 69-73). Curitiba, PR: CRV.

Laplanche, J. (1987). Nuevos fundamentos para el psicoanálisis. La seducción originaria. Buenos Aires, AR: Amorrortu.

Lima, N. L. de (2014). A escrita virtual na adolescência: Uma leitura psicanalítica. Belo Horizonte, MG: Editora UFMG.

Martins, A. (2014). Homo sacers, sujeitos abandonados ao crime. Correio da Appoa, (240). http://www.appoa.com. br/correio/edicao/240/homo_sacer_sujeitos_abandonados_ao_crime/158

Rassial, J. J. (2005). O adolescente e o psicanalista. Rio de Janeiro, RJ: Companhia de Freud.

Rosa, M. D. (2016). A clínica psicanalítica em face da dimensão sociopolítica do sofrimento. São Paulo, SP: Escuta.

Rosa, M. D., \& Domingues, E. (2010). O método na pesquisa psicanalítica de fenômenos sociais e políticos: A utilização da entrevista e da observação. Psicologia \& Sociedade, 22(1), 180-188. http://www.scielo.br/pdf/psoc/ v22n1/v22n1a21.pdf

Sarlo, B. (2013). Sete ensaios sobre Walter Benjamin e um lampejo. Rio de Janeiro, RJ: Editora UFRJ.

Viñar, M. (2009). Mundos adolescentes y vértigo civilizatorio. Montevideo, UY: Trilce. 


\section{Simone Zanotelli Heissler}

Psicanalista membro do Centro de Estudos Psicanalíticos de Porto Alegre (CEPdePA). Mestra em Psicanálise: Clínica e Cultura, pela Universidade Federal do Rio Grande do Sul, Porto Alegre - RS. Brasil. É uma das organizadoras do livro A Analista Grávida (Artes \& Ecos, 2020).

E-mail: simoneheissler@yahoo.com.br

(i) https://orcid.org/0000-0003-1418-0359

\section{Rose Gurski}

Psicóloga e psicanalista, membro da Associação Psicanalítica de Porto Alegre (Appoa). Professora do Instituto de Psicologia e do Programa de Pós-Graduação em Psicanálise: Clínica e Cultura da Universidade Federal do Rio Grande do Sul (UFRGS). Pesquisadora colaboradora do Laboratório de Psicanálise, Sociedade e Política do Instituto de Psicologia USP. Pós-doutoranda do IP-USP. Coordenadora do NUPPEC - Núcleo de Pesquisa em Psicanálise Educação e Cultura (UFRGS). Membro da Rede Internacional Coletivo Amarrações e da Redippol. Autora dos livros Três ensaios sobre juventude e violência (Escuta, 2012) e Retratos da Pesquisa em Psicanálise e Educação (Contracorrente, 2020), Porto Alegre - RS. Brasil.

E-mail: rosegurski@ufrgs.br

(D) https://orcid.org/0000-0002-7392-1463

Endereço para envio de correspondência:

Instituto de Psicologia (UFRGS). Rua Ramiro Barcelos, 2600, sala 232, Bairro Santa Cecilia. CEP: 9003-5003.

Porto Alegre - RS. Brasil.

Recebido 08/11/2018

Aceito 25/09/2019

Received 11/08/2018

Approved 09/25/2019

Recibido 08/11/2018

Aceptado 25/09/2019

Como citar: Heissler, S. Z., \& Gurski, R. (2020). Psicanálise, Vida Loka e Rodas de Escrita com Adolescentes Privados de Liberdade. Psicologia: Ciência e Profissão, 40, 1-14. https://doi.org/10.1590/1982-3703003216281

How to cite: Heissler, S. Z., \& Gurski, R. (2020). Psychoanalysis, Vida Loka and Writing Wheels with Adolescents Deprived of Liberty. Psicologia: Ciência e Profissão, 40, 1-14. https://doi.org/10.1590/1982-3703003216281

Cómo citar: Heissler, S. Z., \& Gurski, R. (2020). Psicoanálisis, Vida Loka e Ruedas de Escritura con Adolescentes Privados de Libertad. Psicologia: Ciência e Profissão, 40, 1-14. https:// doi.org/10.1590/ 1982-3703003216281 